\title{
Gorham-Stout disease in the rib and thoracic spine with spinal injury treated with radiotherapy, zoledronic acid, vitamin D, and propranolol: A case report and literature review
}

\author{
KAZUTAKA KOTO $^{1}$, KENTAROU INUI ${ }^{1}$, MEGUMI ITOI ${ }^{1}$ and $\mathrm{KYOKO} \mathrm{ITOH}^{2}$ \\ ${ }^{1}$ Department of Orthopaedics, Meiji University of Integrative Medicine, Nantan, Kyoto 629-0301; \\ ${ }^{2}$ Department of Pathology and Applied Neurobiology, Graduate School of Medical Science, \\ Kyoto Prefectural University of Medicine, Kyoto 602-0841, Japan
}

Received February 14, 2019; Accepted August 16, 2019

DOI: $10.3892 / \operatorname{mco} .2019 .1934$

\begin{abstract}
Gorham-Stout disease (GSD) is a rare bone condition that is characterized by the spontaneous, idiopathic and progressive proliferation of blood or lymphatic vessels, which replace the bone and marrow space. The precise etiology and pathophysiology of GSD remain poorly understood. Therefore, there is no consensus on the treatment of this disease. In the current study, a rare case of GSD in the rib and thoracic spine with spinal injury that was treated with radiotherapy, zoledronic acid, vitamin D and propranolol, is reported. A 77-year-old man visited the hospital complaining of constipation for 10 days. Within a few days, the patient had recognized complete paralysis of the bilateral lower legs. Radiologically, large osteolytic lesions were confirmed in the 6,7 and 8th right ribs, the 6 and 7th thoracic vertebrae and in the liver and spleen. The lesions were diagnosed as GSD based on clinical findings, imaging characteristics and needle biopsy results. The patient was treated with zoledronic acid, activated vitamin $\mathrm{D}$, propranolol and radiotherapy to the thoracic vertebrae. However, approximately 5 months after the first treatment, the rapidly increasing hemorrhagic pleural effusion compressed the left lung and caused a mediastinal shift to the right thorax. Unfortunately, the patient succumbed to the disease 7 months after first admission. To the best of our knowledge, this is the first
\end{abstract}

Correspondence to: Dr Kazutaka Koto, Department of Orthopaedics, Meiji University of Integrative Medicine, Hiyoshicho, Nantan, Kyoto 629-0301, Japan

E-mail: musclesilva39@yahoo.co.jp

Abbreviations: GSD, Gorham-Stout disease; CT, computed tomography; WIs, weighted images; VEGF, vascular endothelial growth factor; CD, cluster of differentiation; IL, interleukin; CECT, contrast-enhanced computed tomography.

Key words: Gorham-Stout disease, spinal injury, mediastinum shift, intralesional hemorrhage, thoracic spine reported case of GSD in the rib and thoracic spine with spinal injury to be treated with radiotherapy, propranolol, vitamin D and zoledronic acid. Furthermore, there have been no previous reports of a mediastinal shift caused by intralesional hemorrhage in GSD. For future reference, it should be noted that such processes may occur in GSD lesions of the thoracic spine and/or thorax. The present case will therefore contribute to a deeper understanding of GSD, a rare clinical entity.

\section{Introduction}

Primary idiopathic osteolysis is rare and is classified into five types $(1,2)$. Gorham-Stout disease (GSD, also known as 'massive osteolysis,' 'vanishing bone disease,' 'phantom bone disease,' 'Gorham's disease,' and 'Gorham-Stout syndrome') is a type of idiopathic osteolysis and is a very rare bone condition that is characterized by spontaneous, idiopathic, and progressive proliferation of blood or lymphatic vessels that replace the bone and marrow space with fibrous connective tissue (3). The precise etiology and pathophysiology of GSD remain poorly understood. The first reported case of GSD was in 1838 by Jackson (4). Since then, over 300 cases have been reported in the literature worldwide (3). GSD has no predilection for a particular sex or race, and it may occur at any age, although it is diagnosed more often in adolescents and children. Bones are affected in a monocentric manner, although there are reports of continuity to adjacent bone structures (5). GSD affects various bones $(6,7)$. Although the most common initial symptom is a finding of pathological fractures (8), the symptoms of GSD vary and depend on which sites of the body are affected. Because of uncertainty about the underlying cause, the appropriate treatment and prognosis also remain uncertain. A medical approach $(9,10)$, surgery, and radiotherapy (11) are options that have been attempted in isolated cases, with differing degrees of success. Although GSD generally has a good prognosis, life threatening complications may occur owing to the involvement of the spine, viscera, or chest, resulting in chylothorax (12).

To the best of our knowledge, this is the first reported case of GSD in the rib and thoracic spine with spinal injury to be treated with radiotherapy, propranolol, vitamin D, and 
zoledronic acid. Here, we report our experience along with a review of existing literature.

\section{Case report}

We report about a 77-year-old man without any past medical or family history. He visited our department of internal medicine with complaints of constipation continuing for 10 days. A few days later, he recognized weakness and numbness in both legs. These lower extremity symptoms worsened and progressed to paralysis of the 6th thoracic spinal cord within a few days. The neurological status was grade A according to the Frankel scale (13). Radiologically, massive osteolytic lesions were confirmed in the 6,7 and 8th right ribs and in the 6 and 7th thoracic vertebrae, and these lesions invaded into the spinal canal. These lesions were enhanced on contrast-enhanced computed tomography (CT). Furthermore, multiple mass lesions were found in the liver, and a mass lesion was found in the spleen (Fig. 1). Magnetic resonance imaging revealed that the lesions had invaded the 6th thoracic spinal canal, highly compressing the spinal cord. The signal intensity of these lesions was isointense to muscle tissue on T1-weighted images (WIs) and heterogeneously high intensity to muscle on T2WIs (Fig. 2). Blood examination results were mostly normal, with the exceptions of slight elevations in carcinoembryonic antigen $(5.2 \mathrm{ng} / \mathrm{ml})$ and vascular endothelial growth factor (VEGF) levels (Table I).

Based on clinical findings and imaging characteristics, the lesions were diagnosed as cancer metastases. A needle biopsy under CT guidance was performed from the left 6th rib. Microscopic examination revealed a replacement of bone tissue with vascular tissue, and a netlike proliferation of blood vessels similar to capillary vessels consisting of monolayered vascular endothelium. Hyaline fibrous interstitium was also observed. No cellular atypia was present, and an osteoblastic response was also absent. Immunohistochemical examination revealed an overexpression of cluster of differentiation (CD) 34 on vascular endothelial cells and was negative for desmin and D2-40 staining, and the MIB1 proliferation index ranged from 8 to $10 \%$ (Fig. 3). Radiologic imaging combined with histopathology confirmed the diagnosis of GSD. At this time, the patient was introduced to our department. Because 5 weeks had already passed since paralysis had occurred, surgery for paralysis was not performed. First, zoledronic acid (Zometa ${ }^{\circledR}$, $4 \mathrm{mg}$ ) was intravenously administered and was continued once a month for 5 months. Simultaneously, oral administration of activated vitamin D was initiated. One month after the first administration of zoledronic acid, the patient underwent transcutaneous radiotherapy of the thoracic vertebra with a total dose of 20 Gy in 4-Gy fractions once a day for 5 days. Afterward, treatment with propranolol was added at a dose of $0.6 \mathrm{mg} / \mathrm{kg} / \mathrm{day}$. Two months after the first treatment, decubitus was noted around the sacral region, and curettage and medical treatment for the lesion were continued. One month later, a fever caused by pneumonia and/or decubitus was observed, and the fever continued for approximately 2 months despite antibiotic treatment. In addition, a chest $\mathrm{CT}$ scan revealed increasing pleural effusion in the left hemithorax, and thus, a puncture was performed. The fluid was serosanguinous,

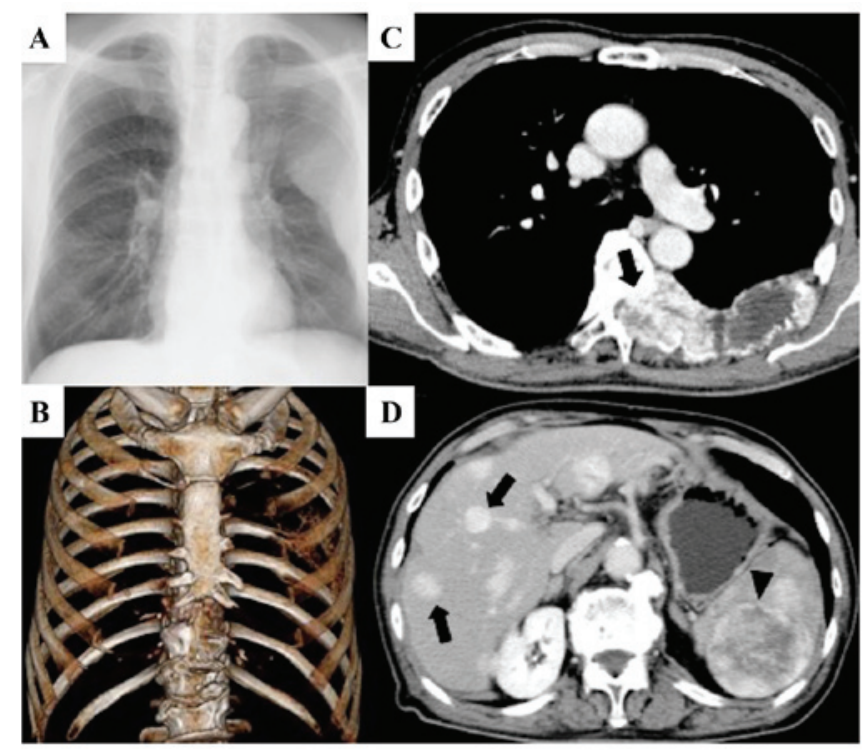

Figure 1. Large osteolytic lesions were confirmed in the 6, 7 and 8 th left ribs and in the 6 and 7 th thoracic vertebra. (A) Roentgenogram of the chest. (B) Three-dimensional CT. (C) CECT scan of the thorax showing that the spinal canal was occupied by these lesions, and the lesions were well-contrasted (arrow). (D) CECT scan of the abdominal region showing that massive lesions were found in the liver (arrow) and spleen (arrow head). CECT, Contrast-enhanced CT.

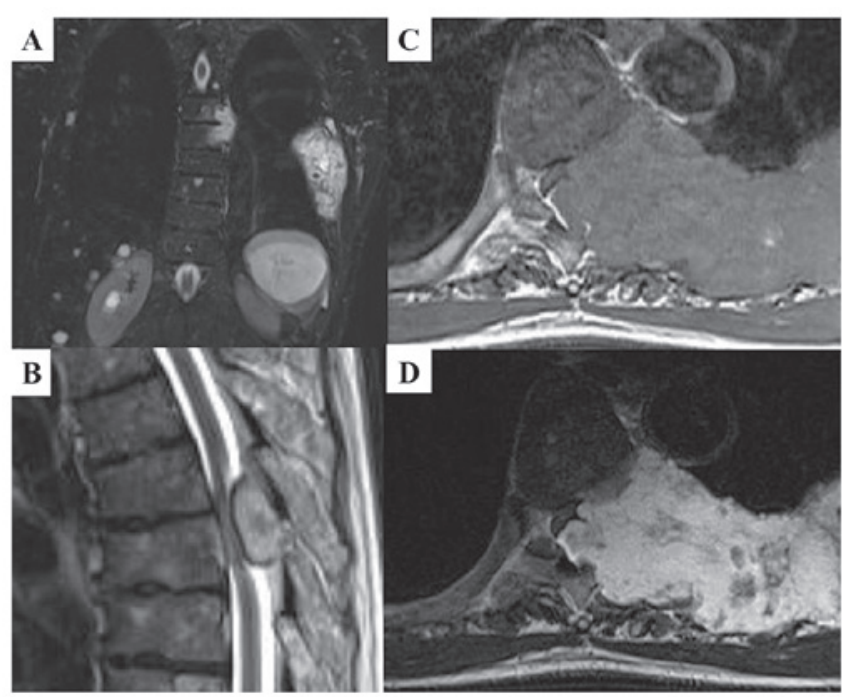

Figure 2. MRI indicating that the lesions had invaded the 6th thoracic spinal canal, and the spinal cord was highly compressed. (A) Coronal images on short T1 inversion recovery. (B) Sagittal images on T2WI. (C) Axial images on T1WI. (D) Axial images on T2WI. T2WI, T2-weighted image.

exudative, and negative for malignancy (Table II). At this time, a CT scan did not show clear progression of osteolysis in the thoracic and rib lesions.

Approximately 5 months after the initial treatment, the hemoglobin concentration suddenly dropped to $4.8 \mathrm{~g} / \mathrm{dl}$. A chest CT scan revealed a remarkably increasing pleural effusion that appeared to be hemorrhagic and was markedly compressing the left lung, causing a mediastinal shift to the right thorax. The patient received several blood transfusions and medication for anemia; however, the condition did not improve. Furthermore, the mediastinal shift worsened rapidly 
Table I. Analyses upon patient admission.

\begin{tabular}{lcc}
\hline Parameter & Value & Reference value \\
\hline Alkaline phosphatase $(\mathrm{IU} / \mathrm{l})$ & 248 & $(109-350)$ \\
Carcinoembryonic antigen $(\mathrm{ng} / \mathrm{ml})$ & 5.2 & $(\leq 5.0)$ \\
Carbohydrate antigen $19-9(\mathrm{U} / \mathrm{ml})$ & 10 & $(\leq 37)$ \\
Prostate specific antigen $(\mathrm{ng} / \mathrm{ml})$ & 1.66 & $(\leq 4.0)$ \\
Protein induced by vitamin $\mathrm{K}$ absence or antagonist-II $(\mathrm{mAU} / \mathrm{ml})$ & 11.8 & $(<40.0)$ \\
Vascular endothelial growth factor $(\mathrm{pg} / \mathrm{ml})$ & 110 & $(\leq 38.3)$ \\
Tartrate resistant acid phosphatase-5b $(\mathrm{mU} / \mathrm{dl})$ & 218 & $(170-590)$ \\
Alubumin $(\mathrm{g} / \mathrm{dl})$ & 3.3 & $(3.7-5.2)$ \\
Total protein $(\mathrm{g} / \mathrm{dl})$ & 6.0 & $(6.5-8.3)$
\end{tabular}

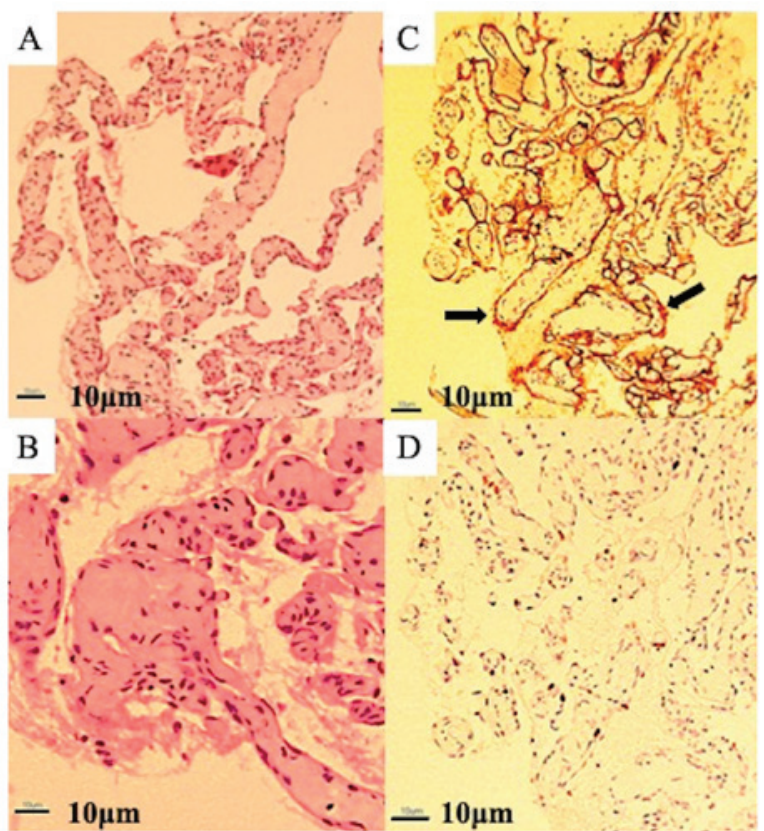

Figure 3. Microscopic examination. (A) Low-powered microscopic examination showing a replacement of bone tissue with vascular tissue and a netlike proliferation of blood vessels similar to capillary vessels consisting of monolayered vascular endothelium (magnification, x40). (B) High-powered microscopic examination showing hyaline fibrous interstitium. No cellular atypia is present, and osteoblastic response is absent (magnification, x100; scale, $10 \mu \mathrm{m}$ ). (C) Immunohistochemical examination showing an overexpression of cluster of differentiation-34 (arrow) on vascular endothelial cells (magnification, $\mathrm{x} 40$ ). (D) The MIB1 proliferation index ranged from 8 to $10 \%$ (magnification, $\mathrm{x} 40$ ). The MIB-1 index was calculated by counting positive and negative nuclei at any 10 hot spots after immunostaining and calculating the ratio visually.

in the subsequent several days (Fig. 4), and the patient's breathing gradually became shallow. Unfortunately, the patient succumbed to the disease 7 months after his initial visit.

\section{Discussion}

In GSD, massive and progressive osteolysis is caused by the abnormal proliferation of endothelial capillaries of vascular or lymphatic origin. The factors underlying the pathogenesis of GSD remain unknown, although various changes in molecular mechanisms have been reported. A high level of
Table II. Biochemical and cytology analysis of pleural fluid.

\begin{tabular}{lc}
\hline Variable & Data \\
\hline Appearance & Serous \\
Protein $(\mathrm{g} / \mathrm{dl})$ & 2.5 \\
LDH (U/l) & 79 \\
Glucose $(\mathrm{mg} / \mathrm{dl})$ & 127 \\
Amilase $(\mathrm{U} / \mathrm{l})$ & 22 \\
Number of cells $\left(\mathrm{mm}^{3}\right)$ & 243 \\
Neutrophil $(\%)$ & 60 \\
Eosinophil $(\%)$ & 0 \\
Basophil $(\%)$ & 0 \\
Lymphocyte $(\%)$ & 32 \\
Methoterial cell $(\%)$ & 5 \\
Histiocyte $(\%)$ & 3
\end{tabular}

Cytology

Negative for malignancy

LDH, lactate dehydrogenase.

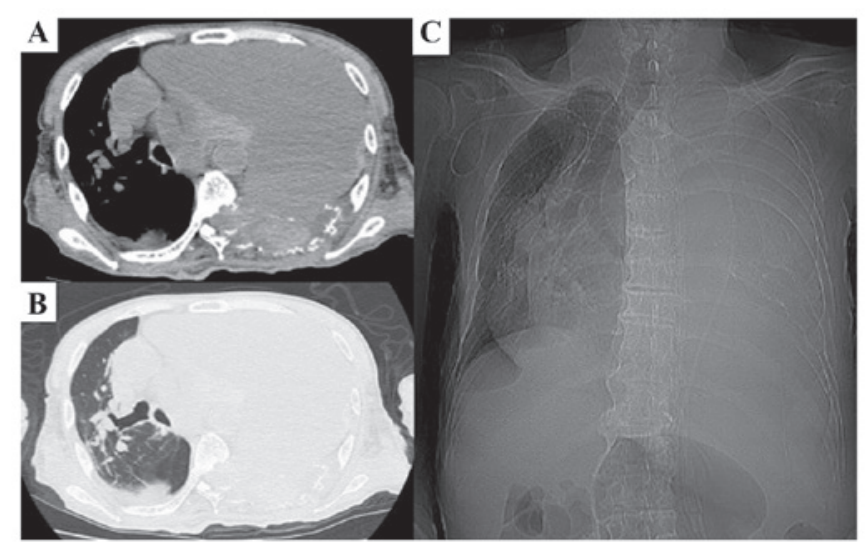

Figure 4. Chest X-ray $\sim 5$ months after the first treatment. (A and B) Computed tomography scan showing a remarkably increasing hemorrhagic pleural effusion causing a mediastinal shift to the right thorax. (A) Mediastinum window. (B) Lung window. (C) Roentgenogram also showing left pulmonary atelectasis and mediastinum shift.

growth factors, such as VEGF-A (14), basic fibroblast growth factor (15), and platelet-derived growth factor-BB (16), have 
been reported in GSD patients, each of which may drive lymphatic endothelial cell proliferation via the mammalian target of rapamycin pathway (15). An increased interleukin (IL)-8 concentration (17) and an overexpression of CD105 (18) were also reported in GSD patients. Overexpression of the growth factors mentioned above may activate endothelial cells and induce angiogenesis, vascular malformation, and lymphangiomatosis.

With respect to the mechanisms of osteolysis, an increased IL-6 level in patients with GSD has been reported (19). IL-6 stimulates osteoclasts, leading to massive bone resorption. As such, IL-6 may play an important role in the pathogenesis of GSD. In addition, homologous monocytic cells producing the osteoclastogenic factors IL-1 $\beta$ and transforming growth factor- $\beta$ have been isolated from GSD patients (17). Furthermore, although the number of circulating osteoclast progenitor cells did not increase, osteoclast precursors showed an increased sensitivity to IL-1 $\beta$, IL- 6 , and tumor necrosis factor- $\alpha$, leading to increased osteoclastic activity (20). Based on these observations, the activation of both endothelial cells and osteoclasts may be a characteristic of GSD.

The shoulder and pelvis are the commonest sites of involvement. However, various locations, such as the humerus, scapula, clavicle, ribs, sternum, pelvis, and femur, can be affected by GSD (21). In spinal GSD, $46 \%$ of cases reportedly occurred in the thoracic vertebrae $(22,23)$. Involvement of both the thoracic vertebrae and ribs is extremely rare, with only three cases being reported in the literature (23-25). One of these reports was a 17-year-old man who had osteolysis in his ribs and thoracic spine, with nonambulatory power in lower limbs due to myelopathy. He received a single dose of $8 \mathrm{~Gy}$ and received $4 \mathrm{mg}$ of zoledronic acid every month for 18 months. Thereafter, posterior instrument fixation with anterior reconstruction was performed. These treatments succeeded in halting the progression of osteolysis and the patient showed complete neurological recovery (23). Another report was for a 2-year-old girl, who had lesions in the femur in addition to the thoracic spine and ribs. In addition, there were hemangiomas in the liver and spleen, and hemangiomatous change on the skin surface of the back. She was treated with IFN $\alpha$ and predonine for 14 months, resulting in an improvement in the progression of osteolysis. 10 months later, there was no evidence of lesion exacerbation, and hemangioma in the back disappeared, and the ribs which had disappeared, reappeared (24). One of the other reports did not describe the clinical course of the patient, and was a report only on imaging findings (25). In current report, the patient's paralysis was complete and the age was relatively high. These are differences from previous reports, therefore age and degree of paralysis might influence on the prognosis.

At present, there is no consensus on treating GSD, and various treatment methods have been attempted, including surgery, radiotherapy, and medications, alone or in combination. Surgery for metastatic spinal cord compression should be performed sooner rather than later. Furthermore, earlier surgical treatment (within $48 \mathrm{~h}$ ) in patients with metastatic spinal cord compression resulted in significantly better neurological outcomes (26). In GSD, the timing of surgery is very difficult because osteolysis continually progresses in its active phase, even after the surgery has been performed. In the current case, surgery was not performed because 5 weeks had already passed since complete paralysis occurred at the time of first visit to our department, and the lesion was considered to be in the active phase based on the progress of paralysis. Moreover, there are no Food and Drug Administration-approved medical therapies for treating GSD. Several drugs have nevertheless been tried, including bisphosphonates (10); interferon alpha-2b (9); the anti-VEGF-A antibody bevacizumab (27); low molecular weight heparin, steroids, vitamin D, and calcitonin (11,28); and sirolimus (8). Bisphosphonates are used owing to their anti-osteoclastic properties. Furthermore, third-generation bisphosphonates have anti-VEGFeffects (29); thus, they have the potential to exert therapeutic effects by inhibiting osteolysis and angiogenesis, vascular malformation, and lymphangiomatosis. The use of propranolol for GSD has been reported previously $(30,31)$. The mechanism of action is considered to be the downregulation of VEGF, which leads to the inhibition of vascular proliferation. It may also inhibit proliferation and migration of lymphatic endothelial cells. In our case, treatment with propranolol was initiated at $0.6 \mathrm{mg} / \mathrm{kg} / \mathrm{day}$, with a plan to gradually increase the dose. However, large decubitus ulcers appeared from the patient's back to his sacrum. Thus, the propranolol dose was not increased because of the possibility that it might adversely influence the healing of the ulcers by inhibiting angiogenesis, which is a known property of propranolol. In fact, serum VEGF levels were not significantly altered before $(110 \mathrm{pg} / \mathrm{ml})$ and after $(118 \mathrm{pg} / \mathrm{ml})$ propranolol administration. Notably, it was reported that a patient treated with propranolol $(2 \mathrm{mg} / \mathrm{kg} / \mathrm{day})$ responded well to this therapy, with resolution of symptoms and reduction in VEGF-A levels after 3 months of treatment to near-control levels (32). The dose of this medication should have been increased if the circumstances allowed it.

Radiotherapy is another treatment modality that has been attempted for GSD. The exact mechanism of action is not known; however, it is postulated that radiotherapy may arrest endothelial cell proliferation and limit the progression of disease $(33,34)$. In a previous case report, although a total dose ranging from 36 to 45 Gy was recommended $(33,34)$, the patient received a transcutaneous radiotherapy dose of only $20 \mathrm{~Gy}$ for thoracic lesions because of concerns around expanding the range of the spinal cord injury and the side effects owing to high dose irradiation. As a result, expansion of thoracic lesions was not recognized on diagnostic imaging; however, bleeding from the lesions eventually became uncontrolled. Based on these findings, it was necessary to reconsider the total dose of irradiation or additional radiotherapy for rib lesions.

In general, the clinical course of GSD varies widely, ranging from spontaneous remission to fatal disease usually in the context of a chylothorax $(35,36)$. In a literature review of 175 cases of GSD, the mean overall mortality rate was $13.3 \%$ (37). The mortality rate of spinal lesion was $20-53 \%(22,37,38)$, and mortality also occurred because of complications of chylothorax. Although chylothorax was not apparent in our case, hemothorax by intralesional hemorrhage did occur, causing a mediastinum shift that finally resulted in the rapid impairment of respiratory function. So far, there have not been any reported cases of mediastinum shift owing to intralesional hemorrhage in GSD, and this is the first report to describe it. For future 
reference, it should be noted that such processes may occur in the thoracic spine and/or thorax owing to GSD lesions.

To the best of our knowledge, this is the first reported case of GSD in the rib and thoracic spine with spinal injury to be treated with radiotherapy, propranolol, vitamin $\mathrm{D}$, and zoledronic acid. Furthermore, no previous reports have described rapid-onset mediastinum shift with respiratory impairment owing to intralesional hemorrhage in GSD. In such rare diseases, conducting large randomized double-blind clinical trials would be difficult; thus, it is essential to record and share experiences obtained with individual treatment methods. Theoretically, effective treatment by clarifying the pathogenesis should be performed, and the results should be shared. This case will contribute to a deeper understanding of the very rare clinical entity of GSD.

\section{Acknowledgements}

Not applicable.

\section{Funding}

No funding was received.

\section{Availability of data and materials}

All data generated or analyzed during this study are included in this published article.

\section{Authors' contributions}

KK made the treatment plan, designed the study and wrote the manuscript. KIn and MI treated the patient and have contributed to data collection and interpretation. KIt performed the histological examination and interpreted the results. All authors approved the final version of this manuscript and agree to be accountable for all aspects of the work.

\section{Ethics approval and consent to participate}

This case report was approved by the Ethics Committee of Meiji University of Integrative Medicine.

\section{Patient consent for publication}

Written and verbal informed consent for publication was obtained from the patient and patient's family.

\section{Competing interests}

The authors declare that they have no competing interests.

\section{References}

1. Torg JS, DiGeorge AM, Kirkpatrick JA Jr and Trujillo MM: Hereditary multicentric osteolysis with recessive transmission: A new syndrome. J Pediatr 75: 243-252, 1969.

2. Macpherson RI, Walker RD and Kowall MH: Essential osteolysis with nephropathy. J Can Assoc Radiol 24: 98-103, 1973.

3. Dellinger MT, Garg N and Olsen BR: Viewpoints on vessels and vanishing bones in Gorham-Stout disease. Bone 63: 47-52, 2014

4. Jackson JSB: A singular case of absorption of bone (a boneless arm). Boston Med Surg J 18: 368-369, 1838.
5. Tolis K, Triantafyllopoulos IK, Tournis S and Papaioannou NA: Gorham-Stout disease of the pelvis: Seven years follow up with complete radiological evaluation. J Musculoskelet Neuronal Interact 16: 79-82, 2016

6. Vinée P, Tanyü MO, Hauenstein KH, Sigmund G, Stöver B and Adler CP: CT and MRI of Gorham syndrome. J Comput Assist Tomogr 18: 985-989, 1994.

7. Szabo C and Habre W: Gorham syndrome: Anaesthetic management. Anaesthesia 55: 157-159, 2000.

8. García V, Alonso-Claudio G, Gómez-Hernández MT and Chamorro AJ: Sirolimus on Gorham-Stout disease. Case report. Colomb Med (Cali) 47: 213-216, 2016.

9. Hagberg H, Lamberg K and Aström G: Alpha-2b interferon and oral clodronate for Gorham's disease. Lancet 350: 1822-1823, 1997.

10. Avelar RL, Martins VB, Antunes AA, de Oliveira Neto PJ and Andrade ES: Use of zoledronic acid in the treatment of Gorham's disease. Int J Pediatr Otorhinolaryngol 74: 319-322, 2010.

11. Yerganyan VV, Body JJ, De Saint Aubain N and Gebhart M: Gorham-Stout disease of the proximal fibula treated with radiotherapy and zoledronic acid. J Bone Oncol 4: 42-46, 2015.

12. Gorham LW and Stout AP: Massive osteolysis (acute spontaneous absorption of bone, phantom bone, disappearing bone); Its relation to hemangiomatosis. J Bone Joint Surg Am 37-A: 985-1004, 1955.

13. Frankel HL, Hancock DO, Hyslop G, Melzak J, Michaelis LS, Ungar GH, Vernon JD and Walsh JJ: The value of postural reduction in the initial management of closed injuries of the spine with paraplegia and tetraplegia. I. Paraplegia 7: 179-192, 1969.

14. Brunner U, Rückl K, Konrads C, Rudert M and Plumhoff P: Gorham-Stout syndrome of the shoulder. SICOT J 2: 25, 2016.

15. Hagendoorn J, Yock TI, Borel Rinkes IH, Padera TP and Ebb DH: Novel molecular pathways in Gorham disease: Implications for treatment. Pediatr Blood Cancer 61: 401-406, 2014.

16. Hagendoorn J, Padera TP, Yock TI, Nielsen GP, di Tomaso E, Duda DG, Delaney TF, Gaissert HA, Pearce J, Rosenberg AE, et al: Platelet-derived growth factor receptor-beta in Gorham's disease. Nat Clin Pract Oncol 3: 693-697, 2006.

17. Colucci S, Taraboletti G, Primo L, Viale A, Roca C, Valdembri D, Geuna M, Pagano M, Grano M, Pogrel AM, et al: Gorham-Stout syndrome: A monocyte-mediated cytokine propelled disease. J Bone Miner Res 21: 207-218, 2006.

18. Franchi A, Bertoni F, Bacchini P, Mourmouras V and Miracco C: CD105/endoglin expression in Gorham disease of bone. J Clin Pathol 62: 163-167, 2009.

19. Devlin RD, Bone HG III and Roodman GD: Interleukin-6: A potential mediator of the massive osteolysis in patients with Gorham-Stout disease. J Clin Endocrinol Metab 81: 1893-1897, 1996.

20. Rossler J, Saueressig U, Kayser G, von Winterfeld M and Klement GL: Personalized therapy for generalized lymphatic anomaly/Gorham-Stout disease with a combination of sunitinib and taxol. J Pediatr Hematol Oncol 37: e481-e485, 2015.

21. Patel DV: Gorham's disease or massive osteolysis. Clin Med Res 3: 65-74, 2005.

22. Tateda S, Aizawa T, Hashimoto K, Kanno H, Ohtsu S, Itoi E and Ozawa H: Successful management of Gorham-Stout disease in the cervical spine by combined conservative and surgical treatments: A case report. Tohoku J Exp Med 241: 249-254, 2017.

23. Srivastava SK, Aggarwal RA, Nemade PS and Bhoale SK: Vanishing bone disease of chest wall and spine with kyphoscoliosis and neurological deficit: A case report and review of literature. Indian J Orthop 51: 107-114, 2017.

24. Takahashi A, Ogawa C, Kanazawa T, Watanabe H, Suzuki M, Suzuki N, Tsuchida Y, Morikawa A and Kuwano H: Remission induced by interferon alfa in a patient with massive osteolysis and extension of lymph-hemangiomatosis: A severe case of Gorham-Stout syndrome. J Pediatr Surg 40: E47-E50, 2005.

25. Ceroni D, De Coulon G, Regusci M and Kaelin A: Gorham-Stout disease of costo-vertebral localization: Radiographic, scintigraphic, computed tomography, and magnetic resonance imaging findings. Acta Radiol 45: 464-468, 2004.

26. Quraishi NA, Rajagopal TS, Manoharan SR, Elsayed S, Edwards KL and Boszczyk BM: Effect of timing of surgery on neurological outcome and survival in metastatic spinal cord compression. Eur Spine J 22: 1383-1388, 2013.

27. Ozeki M, Fukao T and Kondo N: Propranolol for intractable diffuse lymphangiomatosis. N Engl J Med 364: 1380-1382, 2011. 
28. Holroyd I, Dillon M and Roberts GJ: Gorham's disease: A case (including dental presentation) of vanishing bone disease. Oral Surg Oral Med Oral Pathol Oral Radiol Endod 89: 125-129, 2000

29. Koto K, Horie N, Kimura S, Murata H, Sakabe T, Matsui T, Watanabe M, Adachi S, Maekawa T, Fushiki S and Kubo T: Clinically relevant dose of zoledronic acid inhibits spontaneous lung metastasis in a murine osteosarcoma model. Cancer Lett 274: 271-278, 2009.

30. Nir V, Guralnik L, Livnat G, Bar-Yoseph R, Hakim F, Ilivitzki A and Bentur L: Propranolol as a treatment option in Gorham-Stout syndrome: A case report. Pediatr Pulmonol 49: 417-419, 2014.

31. Morimoto N, Ogiwara H, Miyazaki O, Kitamuara M, Nishina S, Nakazawa A, Maekawa T and Morota N: Gorham-Stout syndrome affecting the temporal bone with cerebrospinal fluid leakage. Int J Pediatr Otorhinolaryngol 77: 1596-1600, 2013.

32. Baud J, Lomri A, Graber D and Bikfalvi A: The therapeutic response in Gorham's syndrome to the beta-blocking agent propranolol is correlated to VEGF-A, but not to VEGF-C or FLT1 expression. BMC Res Notes 8: 333, 2015.

33. Heyd R, Micke O, Surholt C, Berger B, Martini C, Füller J, Schimpke T, Seegenschmiedt $\mathrm{MH}$ and German Cooperative Group on Radiotherapy for Benign Diseases (GCG-BD) Radiation therapy for Gorham-Stout syndrome: Results of a national patterns-of-care study and literature review. Int J Radiat Oncol Biol Phys 81: e179-e185, 2011.
34. Dunbar SF, Rosenberg A, Mankin H, Rosenthal D and Suit HD: Gorham's massive osteolysis: The role of radiation therapy and a review of the literature. Int J Radiat Oncol Biol Phys 26: 491-497, 1993.

35. Bode-Lesniewska B, von Hochstetter A, Exner GU and Hodler J: Gorham-Stout disease of the shoulder girdle and cervico-thoracic spine: Fatal course in a 65-year-old woman. Skeletal Radiol 31: 724-729, 2002

36. Rudert M, Gross W and Kirschner P: Gorham-Stout massive ostelysis. A case report. Unfallchirurg 98: 102-104, 1995 (In German).

37. Flörchinger A, Böttger E, Claass-Böttger F, Georgi M and Harms J: Gorham-Stout syndrome of the spine. Case report and review of the literature. Rofo 168: 68-76, 1998 (In German).

38. Lee S, Finn L, Sze RW, Perkins JA and Sie KC: Gorham Stout syndrome (disappearing bone disease): Two additional case reports and a review of the literature. Arch Otolaryngol Head Neck Surg 129: 1340-1343, 2003.

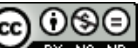

This work is licensed under a Creative Commons Attribution-NonCommercial-NoDerivatives 4.0 International (CC BY-NC-ND 4.0) License. 